\title{
“FLATS” E APART-HOTÉIS EM SÃO PAULO
}

\author{
Antonio Carlos de Lima*
}

\begin{abstract}
RESUMO: Descreve a origem. as denominaçōes e as características dos "flats" e apart-hotéis. analisando a sua evolução na cidade de Săo Paulo. Aborda os seus diferentes públicos. ressaltando a entidade conhecida como "pool". e a concorrência com a hotelaria convencional. Discute o "flat" face ao momento economico atual, e a falta de um planejamento de "marketing" e vendas para maximizar as suas taxas de ocupação e. conseqüentemente, sua performance operacional. Ressalta. tinalmente, a necessidade de um padrāo de serviço e uma clara política de Recursos Humanos.
\end{abstract}

UNITERMOS: Hospedagem: "flat", apart-hotel. "Flat": origem; evolução. Sāo Paulo: "flat".

ABSTRACT: It describes the origin, the denominations and the characteristics of the flats and apar-hotels, analysing its evolution in the city of Säe Pauks. It coments on the different publics, highlighting the phenomenon known as "pool" and the competition with the conventional hotel senice. It points out the flat in contrast with the curreme economic situation and the lack of a planning for marketing and selling to maximize its occupation rates and, consequenth, its operational performance. Finally, it stresses the need of a standard of service and a clear policy of Human Resources.

KEY-WORDS: Hospitality: flat; apart-hotel. Flat: origin; evolucion. Sàc Paulo: flat.

\section{ORIGEM}

Os primeiros projetos de "flat" em Sāo Paulo, cidade pioneira no País, foram lançados há 18 anos por destacada construtora da Capital. A idéia, que teve origem em Nova York, visava dois públicos bem diferenciados, ambos pertencentes às classes mais abastadas:

a) o proprietário-morador que conjugava a um apartamento com dimensões, estrutura e acabamento superiores a um imóvel convencional diziam na epoca as incorporadoras dos empreendimentos, a "mordomia" de um hotel cinco estrelas, quando a expressāo signifi-

(*) Bacharel em Direito pela Faculdade de Direito da Universidade de São Paulo, e em Propaganda e Marketing pela Escola Superior de Propaganda e Marketing. Diretor Superintendente da Rede Paulista de Hotéis e L azer Divisão Flats. 
cava bom gosto no estilo de vida, sem o tom pejorativo dos dias de hoje;

b) o investidor, que ao adquirir um bem de raíz, em constante valorização, aparentemente protegido das alteraçōes da nossa economia, tinha a perspectiva de um rendimento acima da média na sua locação; isto porque esta não é regida pela Lei do Inquilinato, que sempre deixou os proprietários reticentes quanto aos resultados da locação convencional, além de ser palco de rotineiras disputas extraforum e judiciais com os seus inquilinos.

No decorrer da década de 80 , as construtoras indentificaram três principais perfis de consumidores de "flats" na condição de proprietário-morador ou proprietário-condômino:

a) os "yuppies", florescente geração de jovens executivos, especialmente da área financeira e de serviços, que com invejáveis salários faziam reluzir ainda mais o seu "status" morando em "flats";

b) os casais classificados como "terceira idade" que, após verem seus filhos constituirem suas próprias famílias, sentiam que não fazia mais sentido continuar morando em imóveis com várias dependências que lhes ocasionavam problemas com empregados, segurança e sensação de solidão. Para este segmento, o "flat" seria a solução: funcional, com "mordomias", a presença de vizinhos mais jovens e a possibilidade de desfrutar de áreas sociais e de lazer não encontrados em suas casas;

c) os "descasados", principalmente homens, que viam no "flat" uma substituição de sua antiga casa, no que diz respeito aos serviços domésticos, uma conveniência que o imóvel convencional não tem e sem a formalidade e o alto custo de um hotel razoavelmente estrelado.

Assim, qualquer pesquisa imobiliária concluiria que apenas atingindo o público dos três perfis acima e o investidor em imóveis, o filão seria praticamente inesgotável. Os incorporadores, porém, não contavam com dois acontecimentos: a recessão do início da década que teve o seu apogeu em 1983 e a saturação do mercado de "flats", iniciada em 1987, logo após o plano cruzado, que vem se agravando ano após ano, devendo atingir o seu visual mais preocupante em 1992. Nesse ano estarão operando somente na cidade de São Paulo ao redor de 160 condomínios caracterizados como "flats" e assemelhados, alcançando aproximadamente (o número exato é desconhecido) 9.000 apartamentos; ou seja, próximo à oferta da hotelaria da cidade, classificada de dois a cinco estrelas, que está ao redor de 11.000 quartos/apartamentos.

A "febre flatiana" foi tão alta que, de 1981 a 1990, houve, em média, o lançamento de um "flat" por mês. Para efeitos estatísticos, São Paulo é atualmente a cidade com mais "flats" no mundo, superando inclusive Nova York, o berço da idéia. Concluindo, não há mercado (comprador, proprietário, investidor ou inquilino), nem tão pouco renda que possa absorver tamanha oferta. Os "flats" partiram, então, para um outro público, o específico da hotelaria: o hóspede convencional.

\section{DENOMINAÇÕES E CARACTERÍSTICAS}

"Flats", apart-hotéis, hotéis-residência, "suites-flats", "suites-services" são as mais freqüentes denominaçōes desta mesma espécie de condomínio, pois todos são condomínios. As diferenças são sutis. Conceituadamente, entende-se que o "flat" e o "residente service" têm todas as suas unidades voltadas para a hospedagem, sem proprietários moradores. Outra diferenciação está nos serviços oferecidos e no nível do pessoal operacional, que nos "flats" e "residence" estão menos distantes da hotelaria convencional.

Basicamente, são apartamentos de um a três dormitórios, com quarto, sala, banheiro, copa-bar ou cozinha americana, com os serviços básicos de um hotel e, por vezes outros, só encontrados em estabelecimentos de grande porte: recepção, telefonia, mensageiro, manobrista, garagem, arrumadeira, lavanderia, "coffee-shop", bar e restaurante; este último, em "flats" de alto padrão, normalmente de porte médio e de bom conceito entre os "gourmets". E, cada vez mais os "flats" apresentam-se com outros itens de serviço como telex, fax, piscina, sala de ginástica, antena parabólica, central de vídeo, cofres nos apartamentos etc. Assim sendo, para o leigo sob o aspecto estrutural torna-se difícil diferenciar um "flat" com uma sofisticada gama de serviços de um hotel.

\section{3 "POOL" E ADMINISTRADORA}

Sendo o "flat" em "latu sensu" um condomínio, um edifício que foi vendido em unidades para diversos compradores, tem-se dentro do 
empreendimento a convivência de públicos com diferentes caractcrísticas e interesses: o proprietário morador, o hóspede mensalista, o hóspede diarista, o síndico, a administradora e a entidade conhecida como "pool". A conciliação dos interesses de todos não é de fácil solução, especialmente nesta fase de economia recessiva, quando a remuneração do "pool" não atinge níveis satisfatórios e o poder aquisitivo dos potenciais usuários não consegue atender às exigências dos proprietários. Este é um dos principais destaques do "flat" como investimento, pois sendo um imóvel 40 a $100 \%$ mais caro que um convencional, a sua remuneração, atualmente, está muito aquém do desejável.

O chamado "pool" é o conjunto de unidades (apartamentos) destinado à exploração hoteleira, operação realizada por uma administradora especializada, que é remunerada com um porcentual sobre as despesas e outro sobre o resultado líquido. Este resultado (receita da locação menos despesas gerais) conhecido como rateio, é dividido igualmente pelos seus integrantes, independentemente dos apartamentos que ficaram ocupados ou vazios.

A colocação da unidade no "pool" é uma opção do proprietário, que não o integrando dispõe do seu imóvel como bem lhe aprouver. A exigência das administradoras para que a unidade integre o "pool" é que a sua mobília e decoração sejam iguais ao padrão estabelecido quando do início de operações do "flat".

\section{HOTELARIA E "FLATS"}

No seu início, os "flats" alugavam suas unidades por períodos somente superiores a 7 dias, "a semanada", que era o grande diferencial em relação à hotelaria tradicional, a qual opera à base de diárias. O seu público era bem distinto dos usuários de hotéis: pessoas realizando cursos de média e longa duração, pacientes em tratamento e seus acompanhantes, famílias em mudanças para a cidade, ou que estavam realizando obras em suas casas e tinham o "flat" como seu endereço provisório. Hoje, a situação é diferente. Além de atender aos grupos citados, os "flats" vendem diárias e estão se estruturando como hotéis, pois alguns já são projetados com áreas para reuniōes e convenções, segmento de mercado até há pouco tempo era específico da hotelaria.

Os "flats" têm como apelo mercadológico para sensibilizar o usuário padrão de hotel as seguintes características: mais espaço e conforto, localizações nobres, construção recente e principalmente econômica. Por ter um padrão de serviço mais informal, com menos funcionários que também têm menor qualificação e uma extensão de serviços mais reduzida, os "flats" podem atuar no mesmo espaço que a hotelaria, com diárias até $70 \%$ inferiores a hotéis e com estrutura de instalações e equipamentos semelhantes.

Os fatores que justificam o avanço dos "flats" no mercado hoteleiro são: a recessão da economia, quando a procura pelo substitutivo menos oneroso é constante; a conservação do "status", pois com o "down trading" estelar, nesta época de corte de despesas, a substituição de um hotel por outro é sensivelmente notada, especialmente de cinco para quatro e de quatro para três estrelas.

Com a utilização de "flat", o usuário, em especial pessoa jurídica, preserva o status profissional de seus funcionários mais graduados, sem onerar o orçamento específico; e, por fim, acentua-se o modismo na utilização de "flats", principalmente por hóspedes que não se utilizam, habitualmente, de toda a gama de serviços apresentada pelos hotéis quatro e cinco estrelas, como também não exigem uma padronização do nível de serviços dos "flats", aceitando a relativa informalidade em que o mesmo é prestado. Acrescente-se à esta tendência, além dos motivos econômicos, a avaliação subjetiva que o "flat" é uma continuidade da própria casa, por seu espaço e ambientes, com os serviços essenciais e sem o formalismo de um hotel, vantagem que se acentua em estadas mais prolongadas.

\section{MARKETING E VENDAS}

A grande dificuldade encontrada pelos "flats" para maximizar as suas taxas de ocupação e, conseqüentemente à sua performance operacional, é a falta de um planejamento de "marketing" e vendas adequado à sua oferta de unidades para locação. Para o usuário individual, empresa ou agência de turismo, com raras excessões de redes com tradição de mercado, a simples localização de um "flat", seu endereço e telefone, é um obstáculo nem sempre contornado; o que dizer então da descrição de suas instalações, equipamentos e serviços? Promoção de vendas, publicidade, divulgação pela imprensa, folhetos e modernas técnicas de "marketing" e vendas são recursos raramente utilizados pelos empreendimentos, especialmente aqueles pertencentes a pequenas administradoras.

Falta de verba é o argumento mais usado para este distanciamento de mercado; ausência de planejamento seria a resposta mais completa. Exemplificando, se a administradora que tenha 50 apartamentos no "pool", com uma diária média de 45.00 dólares (valores de outubro/91), e ocupação de $60 \%$ ao ano, convencesse os seus "poolistas" 
(proprietários das unidades) a alocar 3\% da receita em "marketing" e vendas, teria a verba aproximada de novecentos dólares mensais. Embora pouco, esse valor é importante para um tipo de negócio que, normalmente, não pode ser localizado nem através do catálogo telefónico, uma vez que na relação de assinantes, o "flat" aparece com a sua denominaçāo jurídica - Condomínio... - que nem sempre coincide ao seu nome fantasia.

Com a situação acima apresenta-se um curioso quadro: de um lado, o mercado comprador cada vez mais receptivo a substituir, em determinados casos e situaçōes, o hotel pelo "flat", não tendo facilidade para localizá-lo; e, de outro lado, com investimentos de vulto no empreendimento e por unidade (hoje, um apartamento de 'flat' de um dormitório, na região dos Jardins, com cerca de $40 / 45 \mathrm{~m}^{2}$ úteis vale de setenta a cento e vinte mil dólares) e, com o "poolista" na expectativa do retorno para seu capital, os "flats" ficam restritos a pequenos anúncios de apartamentos - alugam-se - nos classificados dos jornais. E quando chegam a tanto. Esta insensibilidade para a utilização do potencial dos recursos de "marketing" e vendas prende-se à cultura de administradora imobiliária, onde qualquer despesa é despesa mesmo e nunca in. vestimento, também à falta de uma macrovisão de mercado, gerada principalmente pela ausência nos "flats" de profissionais de hotelaria especialmente de redes nacionais ou internacionais.

\section{PERSPECTIVAS E PADRÃ๑ DE SERVIÇOS}

O quadro é irreversível. Os "flats" estāo em processo de constante ocupação dos segmentos de mercado tradicionais da hotelaria. E, quanto mais instável o quadro econômico do País, mais fortalecida estará a presença dos "flats" junto ao público consumidor; inicialmente, pela economia sem perda da qualidade, ao menos no que diz respeito a instalações e oferta de serviços (o que é diferente do padrão de serviços); em segundo lugar, pelo excessivo número de "flats" em início de operaçōes, sem demanda correspondente, o que fará com que os seus valores de diárias tornem-se ainda mais competitivos em relação aos praticados pela hotelaria.

Cabe ressaltar, finalmente, que o padrão de serviços de um "flat" ou apart-hotel tende a ser inferior a de um hotel com características físicas semelhantes. É importante que o usuário, ou quem por ele atue (o agente de viagens), saiba disto. As diferenças no padrāo de serviço serāo mais sentidas quanto maiores forem as exigências dos hóspedes, principalmente nos seguintes aspectos: funcionários bi ou trilíngues, variedades gastronômicas e utilizaçāo dos serviços, como "room service" entre 0 e 6 horas.

De outro lado, as vantagens de espaço, conforto e "sensaçāo de casa" que os bons "flats" têm, satisfazem ao grande público que se utiliza de hotéis três a cinco estrelas, exceçāo talvez aos cinco estrelas plus, que sāo hotéis com a capacidade de transferir aos seus usuários a sua representatividade social, necessidade profissional ou pessoal que parte do seu público tem, e que os "flats" por mais gabaritados que sejam raramente têm condições de atender. Isto acontece, principalmente, por nāo terem uma forte imagem de mercado, que só acontece com farta utilizaçāo dos meios de comunicaçāo.

Mesmo estabelecidas as diferenciações acima, é importante que as administradoras dos "flats" tenham como objetivo a definiçāo de um padrāo de serviço. Desta padronizaçāo e constante aprimoramento funcional, através de rotineiros treinamentos e uma clara política de Recursos Humanos, por mais simples que seja, surgirá um consistente e fortalecido meio de hospedagem, hoje alternativo, mas em futuro próximo o mais recomendado para determinados públicos. 